\title{
Arabic Learning for Academic Purposes
}

\author{
Ahmad Fatoni \\ Universitas Muhammadiyah Malang, Indonesia \\ E-mail: tonscollect@yahoo.com
}

This study aimed to determine the goal of teaching Arabic for Academic purposes. Teaching Arabic for non-Arabic speakers is generally divided into two types: Arabic language for life, which is a public program in which multiple attributes are related. Learning Arabic is only intended to communicate with Arabic in different situations of life. The second type is Arabic language programs for special purposes, including Arabic for academic purposes (AAP), Arabic for Businessmen People

Abstract $(A B P)$, Arabic for Education People (AEP), Arabic for Objective Purposes (AOP) and others. The researcher in this article focused on the Arabic language teaching program for academic purposes. The method used for this study was carried out using descriptive analysis method which the data were collected from personal interview with students of University of Darussalam Gontor and some documents. The result showed that the successful of teaching Arabic language for academic purposes related to use Arabic language in daily life as well as special activities such as scientific discussions.

\section{Keyword}

Arabic for Academic Purposes; Non-Arabic Speakers; Teaching Arabic

$$
\begin{aligned}
& \text { هدف هذا البحث إلى تحديد تعليم اللغة العربية لأغراض أكاديمية. إن تعليم } \\
& \text { اللغة العربية للناطقين بغيرها بشكل عام ينقسم إلى نوعين: تعليم اللغة } \\
& \text { العربية للحياة، وهي البرامج العامة التى يرتبط فيها متعدد الصفات لا يهدف } \\
& \text { من تعلم اللغة العربية سوى الاتصال بالعربية في مواقف الحياة المختلفة. } \\
& \text { والنوع الثانى هي برامج تعليم اللغة العربية لأهداف خاصية، منها العربية } \\
& \text { لأغراض أكاديمية (AAP)، ومنها العربية لرجال الأعمال (ABP)، ومنها العربية } \\
& \text { لرجال التربية (AEP)، والعربية لأغراض وظيفية (AOP) وغيرها. والباحث في } \\
& \text { هذه المقالة ركز في برنامج تعليم العربية لأغراض أكاديمية. هذا البحث على ولى } \\
& \text { طريقة المنهج الوصفي التحليلي حيث جمع البيانات من المقابلة الشخصياة } \\
& \text { والوثائق. ومجتمع الدراسة و العينة طلبة جامعة دارالسلام كونتور. ونتيجة }
\end{aligned}
$$

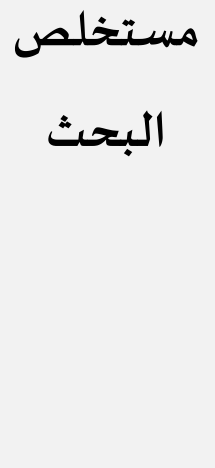

Please cite this article as Ahmad Fatoni. (2019). Arabic Learning for Academic Purposes. Izdihār : Journal of Arabic Language Teaching, Linguistics, and Literature, 2(2), 149-164. DOI: 
البحث تدل على أن نجاح تعليم اللغة العربية لأغراض أكاديمية يتعلق بجعل

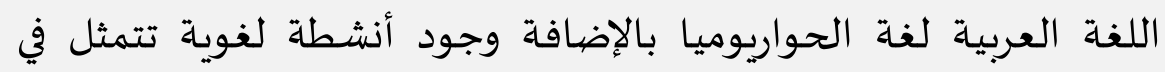

المنقشات العلميية.

$$
\text { كلمات }
$$

مقلدمة

إنّ علم اللغة لهدف عالي لاستلاء الكفاءة اللغوية. ومستخدمة لتلبية حاجة النـاس مثل الاتصـال لطلب المسـاعدة أو لالقـاء الرسـالة. أنّ اللغــة وسـيلة النـاس لتر قيـة سـعاد اجتماعيـا. وأسسس اللغــة آلـة اجتماعيـة اتصـالية لدى النـاس. و. ضـوء ما سبق فإنّ نجـاح بنـاء العلاقـة الاجتمعاعيـة والاتصالية ببن الناس يؤثر عليه الجانب اللغوي الذي ذو كفاءة لغويـة

$$
\text { جيدة(مصطفى \& رحمواتي, IV . (Y). }
$$

كما هو المعروف أن استيعاب المهارة اللغوية العربية من أهم الشروط لطلاب الجامعة و

خاصة الجامعة الإسلامية، و تلك الأهمية تأتي في إجراء الدراسة لفهم الشريعة الإسلامية الصحيحية الدقيقة.(Murdiono, 2018: 154) ومن المؤسف لم يكن كثيرا منهم و أكثرية طلابها الآن خارجي المدارس الثانوية عموما لم يستوعبوا اللغة العربية جيدا. و إذا وجد الماهرون فيها فكان عددهم قليل جدا، وهو من المدرسة الثانوية التي يسكن طلابها في المعاهد المهيأة لهم. أولها برنامج خاص في تعليم اللغة العربية. هذه الحالة تشباء بخرجي الجامعة. ويعرف هذه الحقائق تأتي من عدم قدرتهم على إجابة أسئلة اللغة الأجنبية مثل اللغة العربية عند الالتحاق في الدراسـة العليا لإن

$$
\text { من المواد الممتحنة المهمة هي اللغة العربية. }
$$

تطور تعليم اللغة العربية لأغراض خاصةة بسرعة شديدة. وكانت إحدى تطوراته التي تعد

مرة أيضا يعني اتجاه للتركيز على المتعلم و احتياجه واعتبرها الأسـاس الرئيسي في تصيميم البرنامج، و التطوير الأخر كان في اتجاهـ للنظر إلى اللغة على أنها ليست فقط مجموعة التراكب النحوية و

$$
\text { لكنها أيضيا عدة وظائف.(رحاب, ع ا . آ) }
$$


أن يكون المحاضر لأغراض خاصة على علم بالاحتياجات من تعليم اللغة العبية لأغراض خاصة و إعداد الدنهج التعليمي الذي يواكب. و على المحاضراعداد الدواد الدراسية و الطرى الدستخدمة الدناسبة على الوجو الدطلوب. فلذلك لا بد لدن يهتمبتعليم اللغة العربية أف يراعي

نذه الدشكلات الأسـاسية في لراثث تعليم اللغة العربية لأغراض خاصية.(Nurlela, 2017) وتتبعه المدارس والجامعات في إندونيسيا في تسجيل اللغة العربية في مناهجها. والآن، كثير من المدارس والجامعات التي تطبق دراستـا في تعليم اللغة العربية بالأسـاليب والطرايق الجديدة مثل ما فعله مركز اللغات لجامعاة مولانا مالك إبراهيم الإسلامية الحكومية مالانق حيث تستخدم في تعليم اللغة العربية بالكتاب العربية بين يديك وسلسلة اللغة العربية لأغراض خاصية للمجلات كثيرة منها سلسلة الكتاب لطلاب كلية التربية والشريعة والإقتصادية والنفسية والعلوم التكنولوجيا والطب(Yusuf: 1). و ينقسم تعليم اللغة الأجنبية بإندونيسيا وخاصة اللغة العربية حسب إجراءها إلى ثلاثة أنواع وهي كما يلي: أولا يكون إجراءه مكثفا بالمدة الطويلة وهذا أجري بمؤسسـة فيها شعبة اللغة العبرية كالجامعة الإسلامية أو الجامعة الخاصة في اللغة العربية. ثانيا يكون إجراءه طبيعيا و تقليديا مع المواد الأخرى أو تستخدم إضافية كما جرى بالمعاهد الإسلامية وغيرها. ثالثا يكون إجراءه طبيعيا بالمواد العربية الخاصة بالأوقات المحددة. وهو مثل ما أجري بالمدارس الرسمية الإسلامية كالمدارس الابتدائية و المتوسطة و الثانوية و كذلك بالجامعات الإسلامية حكومية كانت أم أهلية.(Huda, 2015: 462) ورأت جامعة دارالسلام كونتورأن الاستيعاب على اللغة العربية شرط لازم وواجب على كل طالب استيفاءها وخاصـة لمن يقوم بالدراسة الإسلامية و تعميقها كالتفسير والحديث والفقه والعقيدة والتصوف وغيرها من العلوم الإسلامية.

هذا بناء على الحقائق الواقعياة على أن تلك العلوم مكتوبة وموضحة باللغة العربية. ومن المعقول أن من يريد معرفة العلوم الإسلامية فعليه الاستيعاب على اللغة العربية. و ليس من المحتمل أن يفهمها بدون اللغة العربية الجيدة. لذلك الاستيعاب على اللغة العربية واجب على كل طالب عند مؤسسة دراسة الإسلام كجامعة دار السلام كونتور ليستطيع طلابها تعميق العلوم الإسلامية ويطورونها واسعا منطقيا. بناء على ذلك أسست البرامج الخاصة في تعليم اللغة. 
تهدف هذا البرنامج إلى تحقيق مهارة الطلبة في اللغة العربية التي تكون أداة أو مفتاحا في الدراسة الإسلامية. يرجي من هذا التعليم المكثف و الإبداعي بأن يجعل الطلبة قادرين على فهم

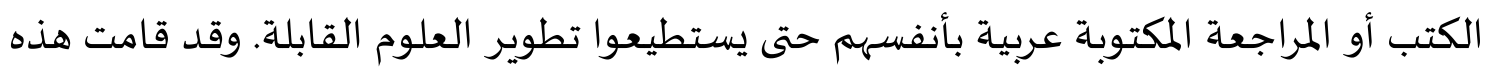
الجامعة بخطواتها الاسراتيجية و اللائمة للحصول على هذا الهدف، و منها تزويد طلابها بمهارة اللغة العربية شفهيا أم تحريريا بوسيلة الاشتراك بالمحاضرة في البرنامج الخاص في تعليم اللغة

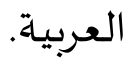

و كتب رشدي أحمد طعيمة و محمود كامل الناقة بأن برامج تعليم اللغة العربية للناطقين بغيرها على شكل عام تنقسم إلى نوعين: برامج تعليم اللغة العربية للحياة، وهي البرامج العامة التى يرتبط بمتعدد الصفات لا يهدف من تعلمه للعربية سوى الاتصال بالعربية في مواقف الحياة المختلفة. والنوع الثانى برامج اللغة تعليم العربية لأغراض خاصة، وهي البرامج التى ينخرط فيها جمهور ذو طبيعة خاصة وحاجات محددة(طعيمة \& الناقة, 7 . . ץ: ـ 1). وتتعدد أنواع هذه البرامج الأخيرة، فمنها العربية لأغراض أكاديمية (AAP)، ومنها العربية لرجال الأعمال (ABP)، ومنها العببية لرجال التربية (AEP)، والعربية لأغراض وظيفية (AOP) وغيرها. وأنواع هذه الأغراض المذكورة تحت مظلة واحدة هي تعليم العربية لأغراض خاصة. كما سبق القول، هناك أنواع كثيرة من برامج تعليم اللغة العربية للناطقين بغيرها. وتتعدد

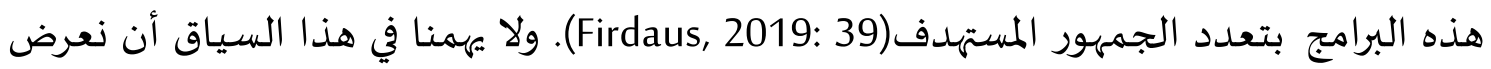
خصائص كل من أنواع البرامج، فهذا البحث يهدف إلى المعرفة الدقيقة و الفهم العميق عن تعليم اللغة العربية لأغراض أكاديمية. و يستخدم هذا البحث المنهج الوصفي بالمدخل التجريبي و يتم البحث في طلبة جامعة دارالسلام كونتور.

\section{نظريات}

\section{تعليم العربية لأغراض أكاديمية}

كما هو المعروف إنّ تعليم اللّفة العربيّة لأغراض أكاديميّة تسمية جديدة لمادة خاصيّة

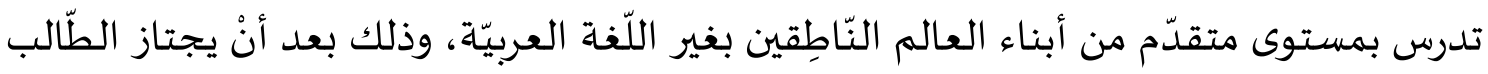

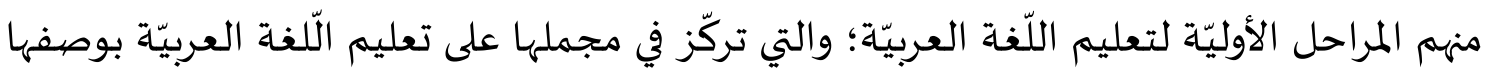


لغة ثانية من خلال مداخل مخصوصية ومحددة وطرائق مجرِّة يتلقى الطّالب فيها القواعد الأسـاسية، ليصل الطّالب إلى مستوى جيد في استخدام اللّفة العربيّة، ثم يأتي مقرر "اللغة العربية لأغراض أكاديمية" توجيهاً لتلك المستويات التعليميّة، حيث في هذا المقرر تتركز معارف الطّالب التي تلقاها سابقاً لتكميل قدرته على استخدام اللّغة العربيّة استخداماً أكاديميًّا، يساعد الطّالب على فهم واستخدام لغة القرآن استخداماً مناسبا بالمستوى الأكاديميّ لإنجاز البحوث العلمية والدّراسـات الإسلامية التي يُكلّف بها في حياته العلميّة ويشتغلها لتطوير مهاراته في الكتابة الإبداعية

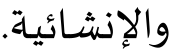

وهذا المقرركما قال إبراهيم أحمد الفارسي بُدئ بتدريسـه منذ سنة لو99 أطلاب الجامعة

الإسلاميّة العالميّة بماليزيا، بعد أنْ أقره المجلس العلميّ للجامعة (Senat) ويحسب أنها الجامعة الوحيدة التي تُقدّم هذا المقرر في اللّغة العربيّة، فهي تعدّ رائدةً لهذا المجال العلميّ لخدمة لغذة القرآن

مداخل اللغة العربية لأغراض أكاديمية خاصةة: ( ) المدخل اللغوي (Y) المدخل المهاري (r) المدخل التعليمي. برامج و مواقف في تعليم اللغة العربية لأغراض أكاديمية خاصية: (1) برنامج تعليم العربية لطلاب الدراسات العليا بأقسام الدراسات الشرقية. وفي هذه الأقسام تنتظم برامج Sanah, لتعليم العربية للطلاب الأجانب. (r) برنامج تعليم اللغة العربية بجامعات في جنوب شرقي (2019

$$
\text { دارس هذا المقرر ومفهوم حاجاته }
$$

إن هذا المقرر يقدّم خصيصاً لدارسي اللغة العربيّة من أبناء العالم الإسلامي الناطقين بغير العبية أصلاً، فقد أُعِدّ لهم هذا المنهج مناسبا لهم، وذلك بوصفها خطوة أولى نحو بناء وتأسيس قدراتهم على استخدام اللغة العربية (تحدثاً، واستماعاً، وقراءةً، وكتابةً) وليس فقط للاستخدام اليومي العادي لأداء العبادات والواجبات الدينية، بل لاستخدامها استخداماً علميًّاً أكاديميّاً، وتوظيفها في البحث العلمي والأدبي توظيفاً إبداعياًَ، وتمكيناً لهم من امتلاك فنون الكتابة الإبداعيـة، والإلقاء الشفوي، وإثارة القضايا ومناقشتها بالإقناع العلمي والبرهنة على الحقائق،

$$
\text { واستخدام المصادر والمراجع، والاقتباس لتأييد وجهات النظر. }
$$


وذلك كله لهدف أسمى هو تمكين أبناء العالم الإسلامي من استخدام لغة القرآن الاستخدام العصري الأمثل في هذا العصر المتقدم، عصر الحاسوب، والإنترنيت، وعصر تقدم

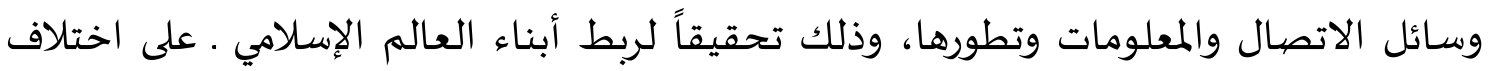
أجناسهم ولغاتهم · بلغة واحدة هي لغة القرآن التي عن طريقها سوف يحققون بها وحدتهم

$$
\text { المنشودة؛ ذلكم الأمل الكبير لهذه الأمة. }
$$

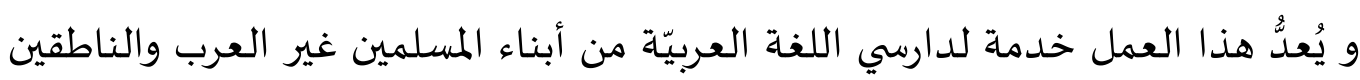

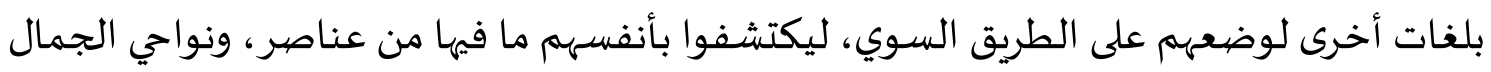

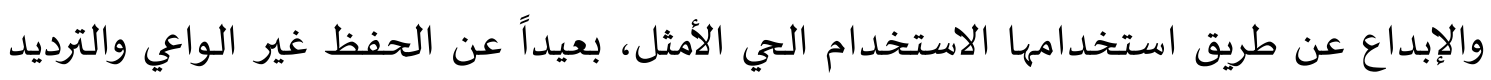

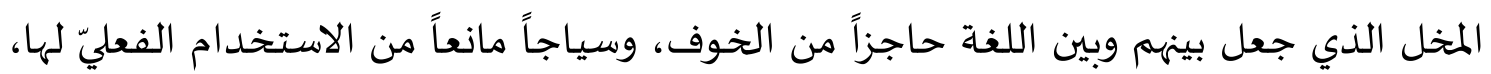
وإذا ما اكتشفوا فهيا تلك النواحي، فحينئذٍ سوف يجدون فيها حلاوة، وطلاوة العربية متذوقين

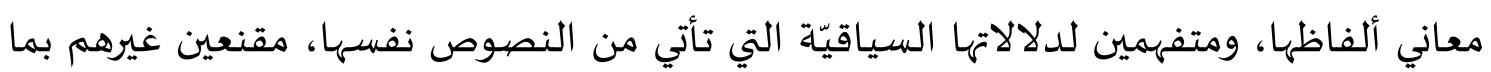
يودون التعبير عنه.

تختلط الأمور أيضاً عند بعض المشتغلين بتعليم اللغة العربية في الجامعات. فبعضهم

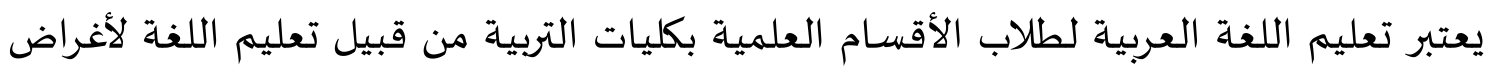
أكاديمية؛ أي لمساعدة الطلاب على الدراسة الجامعية في هذه التخصصات. والواقع أن الأدبيات التربوية تفرق بين الأمرين. وهنا نوضح المقصيود بالتعليم لأغراض أكاديمية كما ورد في الأدبيات. يعرض توني دادلي وماجي لمفهوم تعليم اللغة لأغراض أكاديمية (ضاربين المثل بالإنجليزية)

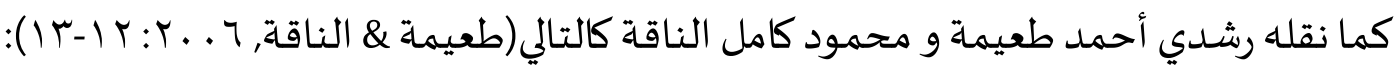

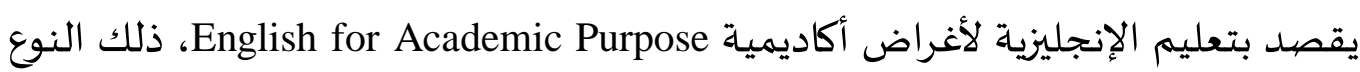
من تعليم الإنجليزية المرتبط بأغراض الدراسة. فأما بالنسبة للطلاب الذين لا ينطقون الإنجليزية

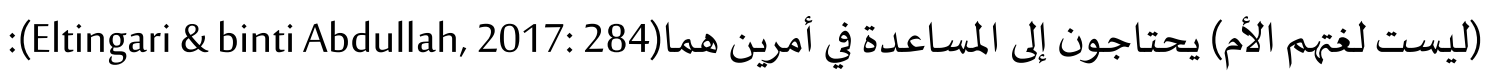
1. اللغة التي يدرسون بها مقرراتهم التخصصية. r. مهارات الدراسة الخاصة التي ينبغي اكتسابها حتى يؤدوا مطالب الدراسة الأكاديمية.

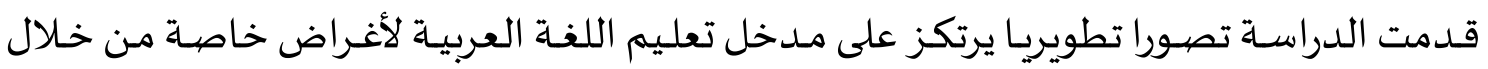

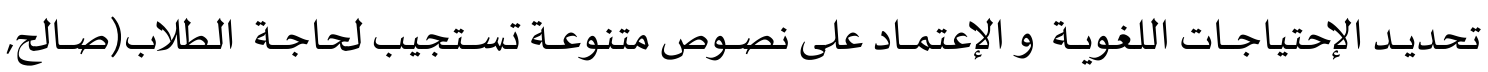


أهداف المقرر واختيار المحتوى

اذا كان يجمع عددا من المفردات تحته فإن السلسلة تزيد بجمع عدد من الجذور تحتها.

وفيما يلي بيان لنموذجي السلسلة التي ترد كما يرد الجذر سلسلة شكلية فقط وسلسلة شكلية دلالية، وذلك على التفصيل التالي: () نموذج السلسلة الشكلية أو الصيوتية للجذور. ب) نموذج السلسلة الدلالية للجذور (جذر الإشتقاق الأكبر)

غياب الاستراتيجية العربية الموحَّدة على غرار الاستراتيجية الأوروبية في تعليم اللغات الحية (ومنها العربية)، وغلبة الرؤى الفردية التي يقدّمها دارسون مختصون، أو مراكز بحثية صغيرة، فيما يتعلق بالجانب النظري والتطبيقي على صعيد بناء البرامج، وغياب الجهود الجماعيّة المتكاملة التي تراكم الخبرات وتستفيد منها، والقصور الواضح في الدراسات التطبيقية التي تقدّم برامج لتعليم العربية لأغراض خاصية، والتداخل بين المفهومات الاصطلاحياة، ولاسيّما العربية للحياة والعربية لأغراض خاصية، وغلبة الطابع الاجتهادي لبرامج العربية لكافة برامج تعليم العربية

لغير الناطقين بها، نتيجة غياب الاستراتيجية العربية الموحدة)(Obeidat \& Mohammed, 2019) يهدف هذا المقرر إلى تزويد الظّلاب النّاطِقِين بغير العربيّة . والمطلوب منهم أنْ يدرسوا مقرراتهم باللّغة العربيّة . بمستوى متقدّم وبمهارات عالية جداً بالنسبة لهم في استخدام اللغة العربية وسيلة للإبداع الأكاديميّ حيث يركّز على تنمية وتفعيل مهارات(Jordan, 1997: (J): ا ـ القراءة: القراءة الفاعلة والواعية (سرعة القراءة ودقة الفهم ) r . المحادثة: محادثة واقعيّة مفهومة بوضوح تعتمد على البرهان والدّليل. r. الاستماع: فهم متكلمي اللّغة مرادهم فهماً مباشراً (الاستماع الاصطفائيّ).

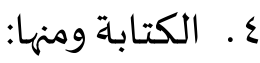

$$
\text { ب. }
$$

ج. الكتابة الإبداعيّة، ومنها اليوميات، والقصص، والشّعر. د. الكتابـة الوظيفيّة والإبـاعيّةـة. ومن نمطها (الرّسـائل الرسـميّة والإخوانيـة بطاقـات

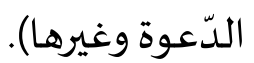


ونحسب أنّ هذا يمكّن الطّالب ويعده لامتلاك مهارات كتابة النّصوص الأكاديميّة مثل المقالة العلميّة أو البحث الفصليّ أو الماجستير أو الدكتوراه.

يأتي هذا المقرر بوصفه خطوة من خطوات تعليم اللّغة العربيّة، خطوة متقدمة تكميلاً للخطوات السيّابقة الأولية، فهو يُعدُّ خطوةً مبكرة جداً؛ من أجل تثقيف الطّالب غير العربّي، وتعريفه بأصالة الفكر الإسـاميّ وبيان الرسالة الفكريّة للغة العربيّة لغة القرآن ومهاراتها العُليا، وتنوع مجالات الإبداع، وذلك بالضرورة يعمل على إبراز دور العلماء المسلمين والعرب خاصيّةً في مختلف المعارف الإنسانيّة. أسـاس تعليم المقرر

رأى بعض الباحثين أنّ لكلّ عمل أونشاط تعليمي أسـاس نظري ينطلق مناه ويؤسس عليه، ولهذا فمن الواجب علينا أنْ نوضح الأسـاس النظري لعملنا هذا. ومن المعلوم أنّ دارس هذا المقرر ليس من أبناء اللغة العربيّة فهو دارس للغة العربيّة بوصفها لغة ثانية في بيئة بعيدة عن واقع اللغة العربيّة، وهذا النوع من الدارسين غير العرب بهذه المواصفات تقدّم له اللّغة العربيّة عن طريق عدة مداخل، وأسس نظريّة أهمها(الفارسي, ع . . ب). إنّ ما يناسب الدارس الناطق بالعربيّة لا يناسب الدّارس النّاطق بغيرها من حيث طرائق التدريس ومنهجياته المعتمدة. إنّ اكتسـاب مهارات اللغة العربية يبدأ بالتعرّف، ثم الاستيعاب، ثم الاستماع، ثم الممارسـة المتكاملة للغة العربيّة، تحدثاً وكتابةً. إن أقرب طريق لتعليم اللّغة العربيّة للنّاطقين بغيرها يلتزم بـ ا ـ استخدام اللّغة العربيّة الاتصاليّة المتكاملة "التّعبيريّة المباشرة، . r . . مراعاة ظروف وأحوال بيئة المتعلم بدلاً من بيئة معينة غير مناسبة. r. ََلْق جوّ مناسب وظروف تساعد على تعليم اللغـة الأخرى. ع ـ البعد عن استخدام العاميات واللهجات المختلفة. ه. استخدام اللّغة العربيّة الفصحى المعاصرة التي يفهمها الجميع بسهولة. الاستفادة من معطيات العصر الحـديث المتقدّمة من وسـائل تعليميّة مثل معامل اللغـات . الكمبيوتر ـالإنترنيت .قاعة الفيديو ... وغيرها. البعد عن التلقين النّظري والاعتماد على التدريب العمليّ والممارسـة الفعلية للغة. 
الاستفادة من الخبرات والممارسات العملية لتدريس اللّفة العربيّة للنّاطقين بغيرها. ومن خلال تلك المنطلقات كان انطلاقنا نحو تدريس "اللغة العربية لأغراض أكاديمية" معتمدين على تلك الأسسس والمبادئ العامّة سعياً وراء تحقيق أقصى فائدة من خلال خطة تركّز على: ا ـ اتخاذ الفصل قاعة الدراسـة مسرحاً لممارسـة مهارات اللغة: استماعاً وتحدثاً وكتابة، وقراءة، بدلاً من الاعتماد على التلقين والحشو الذهني المنفر من التعلّم. r r . الاستفادة من خدمات الجامعة وتجهيزاتها الجامعة مثل:

اسـتخدام قاعـة الفيـديو للاسـتماع والمشــاهدة ،وعقـــ محاضـرة أسـبـوعياً طـوال الفصـل الدراسيّ، حيث تسـاعد هذه المحاضـرات التثقيفيّة على الاستماع الاصـطفائي لتعزيز مهارة

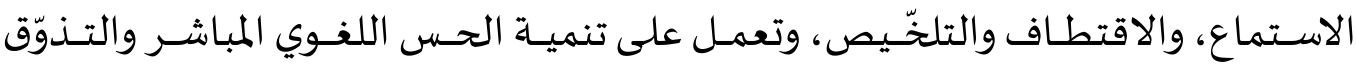
الجمالي لمعاني وأساليب اللغة العربيّة. استخدام معمل الكمبيوتر اللغوي الحـديث المرتبط بشبكة المعلومات (الإنترنيت)، بهدف التأكيد على الجانب العملي والتطبيقي، والاهتمام بالجانب الوظيفي المتصيل بحياة الطالب المستقبلية وتنميـة قدرات كل طالب وإشباع ميوله وتحقيق فائدة جادة لله. مع تدرببـه على طرق جمع المعلومات بعيداً عن الوسـائل التقليدية القديمهة. عقد محاضـرات عامـة، باســدعاء محاضـرين متخصصيـن من الجامعـة وذلك بهـدف تنوّيـع مصادر علم الطالب وتعدد معارفه الأكاديميّة. تــدربب الطلاب على المنـاظرة العلميّـة وأسـلوب المناقشـة الأكاديميّة والـدفاع عـن وجهـات النّظر بالحجج المنطقية، والإقناع العقليّ. تـــريب الطالب على العـرض الشـفوي باسـتخدام وسـائل متقدّمـة عـن طريـق الكمبيـوتر، وجهاز العرض الرأسي بأشعة الليزر. القـدرة على التِّعلم الـذاتي، والإبــاع، واكتســاب المهارات، والخبِرات عـن طريـق توظيـف التقنيات التربويّة، والوسائل السّمعيّة والبصريّة التي تسـاعد على نجاح الطالب باستفادته من خبراته بالممارسـة المباشرة. 
r. تقديم كراسة تطبيقات عمليّة الأكاديميّة للطالب ليقوم بالتدرب بشكل إيجابي على ممارسة

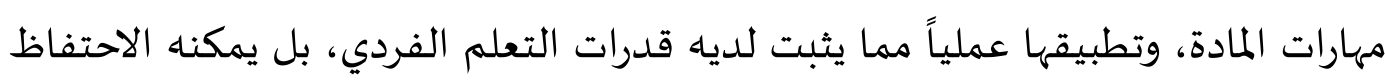

$$
\text { بهذه الكراسة بوصفها سجلاً لأعماله. }
$$

و أما طريقة لتأليف الكتاب لأغراض خاصة هو أن تكون المواد المختارة مرتبطة بحياة الطلاب

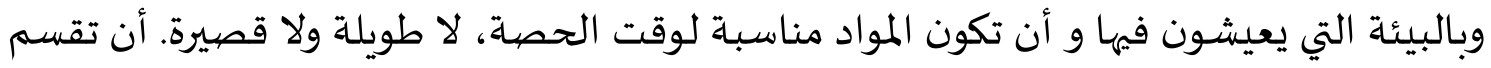
المواد المقررة إلى وحدات توزيع على أشهر وسنة (Ghufron, 2019).

\section{طريقة البحث}

المنهج المستخدم في هذاالبحث هو المنهج الوصفي. يقصد بالمنهج الوصفي هو أحد أشكال

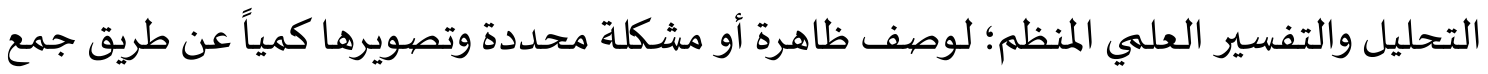
بيانات ومعلومات مقننة عن الظاهرة أو المشكلة وتصنيفها وتحليلها وإخضاعها للدراسة الدقيقة.

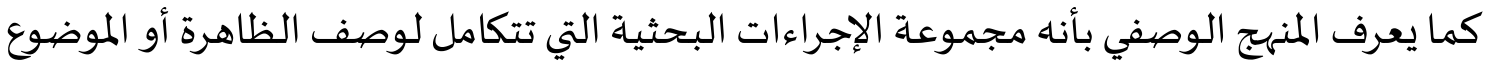
اعتماداً على جمع الحقائق والبيانات وتصنيفها ومعالجتها وتحليلها تحليلاً كافياً ودقيقاً:

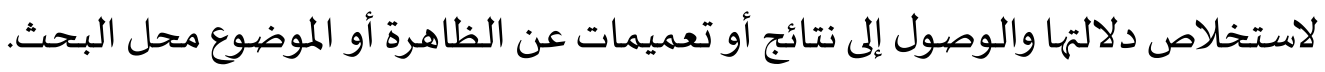

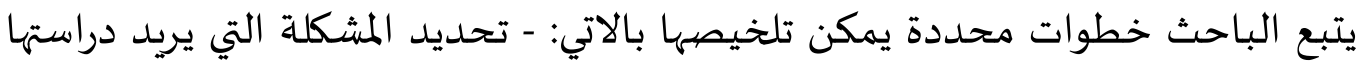
تحديداً دقيقاً. - تحديد الاهداف. - تحديد طرائق جمع المعلومات والبيانات والتحقق من صهلاحية الأدوات المستخدمة في ذلك وصدقها. - تطبيق أدوات البحث بطريقة دقيقة ومنظما وموضيوعية. وصف النتائج وتحليلها وتفسيرها في عبارات دقيقة بسيطة واضحة. - و استخلاص التعميمات والوصهول الى الحقائق.

\section{بحث و مناقشات}

تجربة تعليم العربية لأغراض أكاديمية في جامعة دار السلام كونتور تلك هي منهجيّة تعليم اللغة العربية للأغرض الأكاديمية التي التزمناها منذ بداية تعليم

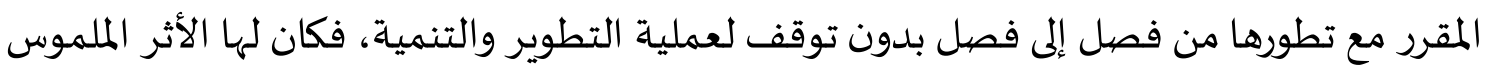
والفعّال لدى الطلبة الذين سيلتحقون 
أسست جامعة دار السلام كونتور في عام r197 و قامت بتنفيذ أنشطتها التعليمية الأكاديمية والاأكاديمية بجميع مرافقتها مثل المسجد و السكن و المكتبة و معمل اللغة و معمل الحاسوب و الملعب و مننظمات الطلبة و غيرها من وسائلها التربية التعليمية يكون في حرم واحد، فيسهل بذلك عملية التربية والتعليم. كما أنها تتميز باستخدامها اللغتين الإنجليزية والعربية كلغتي التدريس في الفصول الدراسية لمواد الدراسات الإسلامية و اللغة العبية، وكتابة البحوث العلمية وغيرها من الأنشطة الجامعية("رسالة آخر السنة الدراسية حبـ / ه . . ب,"). ومن أهم النظريات التي اطمأن إليها الجامعة ضرورة إيجاد بيئة لغوية يتدرب فيها الطلبة على النطق باللغة الإنجليزية والعربية. فاللغة أسـاس الكلام، و مهارة الكلام لا تأتي إلا عن طريق الممارسة المستمرة و التدريبات المتواصلة، ولذلك يشجع الجامعة طلابها على الكلام بهاتين للغتين في معاملتهم اليومية من خلال الأنشطة المختلفة، منها إنشاء مركز إحياء اللغة، إنشاء النوادي اللغوية ونشر الكتابات و اللافتات والمفردات باللغة الإنجليزية والعربية، و الخطابة المنبرية، والمسابقة التمثيلية، و إصدار المجلات الحائطية وغيرها. من هذه الأنشطة كلها يكسب الطلاب مهارتهم اللغوية. والحق أن منهج جامعة دار السلام في كونتور لا يختلف من وزارة الشؤون الدينية، إلا أن هناك بعض الزيادات والتغيرات التي تراها الجامعة ضرورية. تتمثل هذه الزيادات و التغيرات في بعض المواد المتعلقة بتأهيل المهارات اللغوية، فمادة اللغة العربية -على سبيل المثال، ترى الجامعة ضرورة زيادة حصتها فأصبحت ست حصص بعد ما كانت أربع حصص طبقا للمنهج الصيادر من الوزارة، وذلك لتوسيع المجال أمام الطلبة للتطبيقات النحوية والبلاغية من الموضوعات التي درسوها في المراحل السابقة.

فإذا عقدنا مقارنة بين منهج الجامعة و المنهج الصيادر من الوزارة بخصوص المواد العربية، نجد أن الجامعة قد زادت في ساعتها الدراسية V سـاعات و قللت منها حصية واحدة.

الجدول 1 ـ عدد الساعات الدراسية لتعليم اللغة العربية في جامعة دار السلام كونتور

\begin{tabular}{|c|c|c|c|}
\hline \multicolumn{2}{|c|}{ عدد السـاعات الدراسية } & \multirow[t]{2}{*}{ 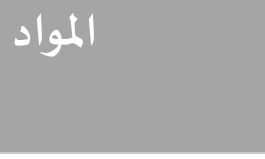 } & \multirow[t]{2}{*}{ 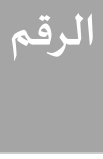 } \\
\hline منهج الوزارة & منهج الجامعة & & \\
\hline$\varepsilon$ & 7 & اللغة العربية & 1 \\
\hline$\varepsilon$ & 7 & النحو & $r$ \\
\hline
\end{tabular}

Please cite this article as Ahmad Fatoni. (2019). Arabic Learning for Academic Purposes. Izdihār : Journal of Arabic Language Teaching, Linguistics, and Literature, 2(2), 149-164. DOI: https://doi.org/10.22219/jiz.v2i2.10096 


\begin{tabular}{|c|c|c|c|}
\hline$r$ & $\varepsilon$ & الصرف & $r$ \\
\hline$r$ & r & الاستماع & $\varepsilon$ \\
\hline$\varepsilon$ & r & المحادثة & 0 \\
\hline$r$ & 7 & المطالعة & 7 \\
\hline$\varepsilon$ & $\varepsilon$ & التعبير & $V$ \\
\hline$r \varepsilon$ & $r$. & المجموع & \\
\hline
\end{tabular}

نرى من خلال الجدول ا السابق أن تقليل الساعة الدراسية يتم من خلال تعليم مادة المحادثة، و ذلك لاعتبار واحد، و هو أن الجامعة قد جعلت اللغة العربية لغة الحوار بين الطلبة و المدرسين داخل الفصول الدراسية وخارجها، بالإضـافة إلى وجود أنشطة لغوية تتمثل في المناقشـات العلمياة التي يعقدها الطلبة خارج السـاعات الدراسية و غيرها من الأنشطة التي تدعم الطلبة في مهارة الكلام.

فالجامعة لم تخصص لتلك المواد الخاصة لتنمية مهارات اللغوية سوى 0،17 \% من

حصص المنهج، و ذلك لأن التدريبات اللغوية تتم عن طريق استخدامها خارج الفصول الدراسياة. إن الطريقة المباشرة التي طبقها جامعة دار السام كونتور في تعليم اللغة الغربية قد آتت بثمارها بعد مرور عدة سنوات. فقد تخرج مناه طلاب يجيدون هذه اللغـة إجادة تمكنهم من متابعة دروسهم للتحاق الدراسـة العليا في جامعات في البلدان العربية. أمامنهج قسم تعليم اللغة العربية في جامعة دار السام كونتور يتمثل في عناصر رئيسية آتية : ا ـ المواد الدينية، مثل الفقه، و التفسير، و الحديث وعلومه، و علوم القرآن و غيرها. r. المواد اللغوية،، مثل علم اللغة، و علم الأصيوات، والنحو، و الصرف و غيرها r. المواد التربية و التعليمية، مثل علم التربية، و طرق تدريس اللغة، و علم النفس و غيرها. إن جامعة دار السلام كونتور قد أدخلت المنهج الدارسي الخاص لقسم تعليم اللغة العربية موادا لهم تكن موجودة في المنهج الصادر من الوزارة، و هي بمثابة المحاولة لتوسيع معرفة الطلبة و ثقافتهم اللغوية العربية. و تتمثل هذه المواد فيما يلي: 1 - - علم اللغة النفسي (ساعتان) 
تعتبر الحامعة هذه المادة من أهم مواد قسم تعليم اللغة العبية لأهها تساعد الطلبة في التعرف على مراحل النمو اللغوي للإنسان. علما بأن معظم الطلبة هذه الجامعة يقومون بتدريس اللغة العربية في المراحل الإعدادية و الثانوية في معهد دار السلام الحديث. r - ( - علم المعاجم (ساعتان)

تهدف هذه المادة إلى تعريف الطلبة بالمعاجم العبية و ما يتميز بها كل معجم وما يؤخذ عليه من المآخذ. و تؤخذ مادة التدريس من كتب علم المعاجم ، مثل "البحث المعجمي و مدارسه" للدكتور عبد المنعم محمد النجار و غيره من الكتب.

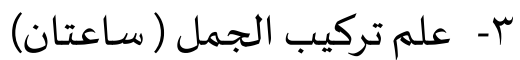

تهدف هذه المادة إلى تعريف الطلبة بالعلاقة بين البنية الجمل ووظائفها ثم العلاقة بينها و مقاماتها، إلى جانب تعريفهم بالأسـاليب العربية، مثل أساليب التوكيد، و أساليب الإشتغال، و أساليب الاستغاثة ة الندبة. و تؤخذ مادة التدريس من "مذكرة خاصية في علم تركيب الجمل " لعبد الحافظ زيد. و من "ملخص قواعد اللغة العربية" لنعمة فؤاد، و "جامع دروس العربية “ للشيخ مصطفي غلاييني و غيرها من الكتب. ع- تاريخ الأدب العربي (ساعتان)

تهدف هذه المادة إلى تعريف الطلبة بتاريخ الأدب العربي بشكل مجمل و تعريفهم بما يتميز باه كل عصر من العصور التي يمر بها الأدب العببي. من خلال هذا الدرس أيضيا يتعرف الطلبة على بعض النصوص الأديبة التي سيدرسونها بنوع من التفصيل في الفصل الدراسي القادم. و تؤخذ مادة التدريس من كتاب "تاريخ آداب اللغة العربية" لجرحي زيدان و غيره من الكتب. هذا وكانت الجامعة عند وضعها هدا المنهج وضعت نصب عينيها مصلحة هذا الدين الحنيف.و كل مادة تضعها الجامعة ترمي من ورائها إلى ترسيخ العقيدة الإسلامياة الصحيحة في نفوس الطلبة و المدرسين، ومن خلال فهم مصادر هذا الدين باللغة العربية التي كتبت فهها يدفع الطلاب على النطق بها. أثر المنهججية

لعله من المفيد في هذا المدخل التعريفيّ بالمادة أن نتحدث بإيجاز عن تجربة وخبرة تعليم اللغة العربية لأغراض أكاديمية، وذلك الأمر يقتضي منّا أن نبيّن إلى أي مدى كان تأثير دراسة وتدريس 
هذا المقرر على الطالب الدارس، والمعلم المُدرس تربويّاً، ونفسيّا،وومن الأفضل تناول ذلك على النحو

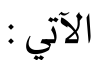

$$
\text { أولاً: على مستوى الطالب الدارس }
$$

لقد لاحظنا أثناء تدريس لهذا المقرر أن الطالب دارس هذا المقرر تميّز بما يلي:

$$
\text { ( أ ) نفسياً: من حيث السلوك النفسيّ والشعور الوجدانيّ : }
$$

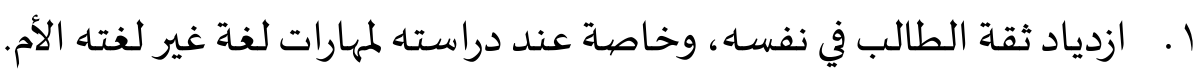

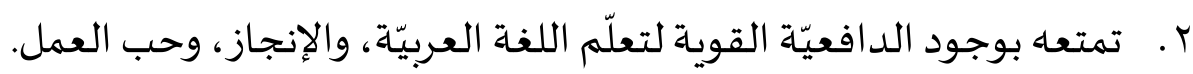
r. . تحقيق الإنجاز عن طريق مسايرة الأقران والتفاعل الجماعيّ من خلال الأنشطة.

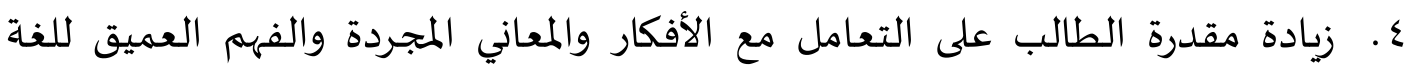
العربية، بل والوصول إلى مرحلة إنتاج الأفكار باللغة العبيّة، مع كونها لغة ثانية.

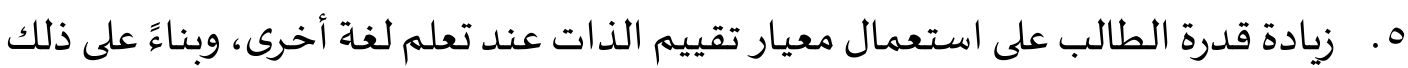
فسوف يتمكّن من التعرف على مستواه الحقيقي، وعلى مدى تقدمه في تحصيل اللغة

$$
\text { ومعارفها، واستعمالها فيشعر بدرجة نجاحه في استخدامها. }
$$

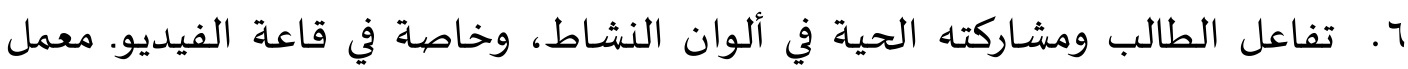
الكمبيوتر. المحاضرات العامة- قاعات الاطلاع بالمكتبة . إعداد وتنظيم البرامج والأنشطة

$$
\text { الطلابية، كالمناظرات، و تدريب الطالب على مهارات البحث العلميّ. }
$$$$
\text { V. الإحساس بالمسؤولية وربط تعلم اللغة بطموح الطالب، وحاجات المجتمع . }
$$

$$
\text { (ب) مهاريّاً: من حيث إتقان واستخدام مهارات اللغة العربيّة: }
$$

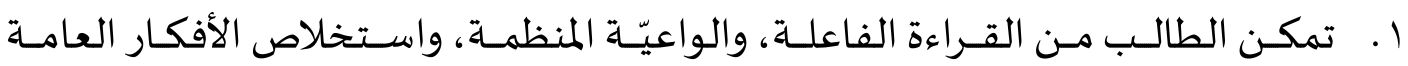
والجزئية، وتحليل المفردات، وتركيب وبناء الجمل تركيباً نحويًاً سليماً. r. الربط بين جملتين نحوياً باستخدام أدوات الربط والألفاظ المفتاحية.

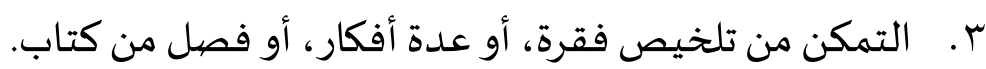
ع. كتابة عبارات وجمل سليمة حول مواقف طبيعيّة مألوفة. 0. صوغ الأسئلة واستخدام أسلوب الاستفهام أثناء الحوار . I. توظيف علامات الترقيم فيما يكتبه الطالب توظيفاً جيّداً. 
V. استخدام مفردات اللغة في التخاطب اليومي، مع توظيف المفردات الجديدة التي يتعلمها

$$
\begin{aligned}
& \text { الطالب في خطابه اليومي، فضلاً عن إجادة الأسـاليب البلاغيّة. } \\
& \text { ^. . استخدام القواعد النحويّة :كتابةً، وقراءةً، وتحدثاً. } \\
& \text { 9. القدرة على التواصل الجيّد والفعال مع معطيات التراث العربيّ والإسلاميّ. } \\
& \text { ثانياً: على مستوى المعلم }
\end{aligned}
$$

أما من حيث توضيح ذلك فنجد أن غالبية مَنْ دَرَُّوا هذا المقرر كانوا متجاوبين ومتفهمين

لفلسفة المنهج مما أهّلهم للإبداع والابتكار، والتفاعل مع المادة، حيث كانوا على قدر من المسؤولية والالتزام، هذا في الغالب الأعم، فضلاً عن أن هناك من يُدَرِّس هذا المستود على هواه معترضياً حيناً، ومعارضياً حتى نفسها حيناً آخر .بطريقة روتينيّة جامدة بعيدة عن الإبداع والابتكار، على الرّغم من أنها لدياه الحرية المطلقة للإبداع، تلك الحرية التي لا يتيحها لهم مقرر آخر.

\section{خاتمة}

تلك هي منهجيّة تعليم اللغة العربية للأغرض الأكاديمية التي التزمت جامعة دار السلام في

كونتور منذ بداية تعليم المقرر مع تطورها من فصل إلى فصل بدون توقف لعملية التطوير والتنمية، فكان لها الأثر الملموس والفعّال لدى الطلبة الذين سيلتحقون بالدراسـة على سبيل المثال. في جامعة الأزهرالشريف أو جامعة المدينة المنورة و غيرهما، فأحسوا بفائدتاه وجدواه، لأنهم مارسـوا خبرات هذه المادة بعيدةً عن طرائق التدريس التقليدية التي أماتت فصاحة اللغة العربية بالجمود عند طرائق تدريسية تعتمد على التلقين والحشو المقنن ولا يفيدكثيرا للطالب.

$$
\text { قائمة المراجع }
$$

Eltingari, S. M., \& binti Abdullah, N. S. (2017). Tahlîl Al-Hâjât Al-Khâshshah li Muta'allimî Al-Lughah Al-'Arabiyah li Aghrâdh Khâshshah. Arabiyat: Jurnal Pendidikan Bahasa Arab dan Kebahasaaraban, 4(2), 282-299.

Firdaus, M. (2019). Problems in Expressing Arabic Language of Indonesian Students at Khartoum International Institute for Arabic Language. Izdihar: Journal of Arabic Language Teaching, Linguistics, and Literature, $2(1), 35-52$. 
Ghufron, B. (2019). Curriculum of Intensive Arabic Lessons For The Language Center at The University of Darussalam Gontor. Educan: Jurnal Pendidikan Islam, 3(2), 160-180.

Huda, M. (2015). Ta'lîm al-Lughat al-'Arabiyyah li Aghrâdh Khâshshah. Paper presented at the Majmu' Buhuts: Al-Lughat al-'Arabiyyah Asâs alTsaqâfat al-Insâniyyah,.

Jordan, R. R. (1997). English for Academic Purposes A Guide and Resource Book for Teachers. Cambridge: Cambridge University Press.

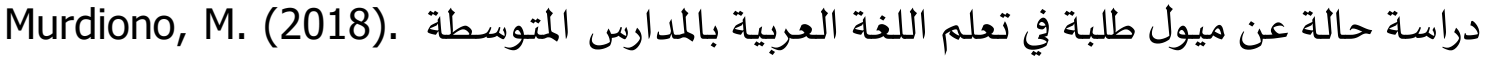
الإسلامية بمالانج وباتو. Izdihar: Journal of Arabic Language Teaching, Linguistics, and Literature, 1(2).

Nurlela, N. (2017). تعليم اللغة العربية لأغراض خاصة: تطبيقه لطلبة التمريض. Al-Manar, $\pi(1), 81-90$.

Obeidat, R. A., \& Mohammed, A. (2019). تعليم اللغة العربية للناطقين بغيرها بين

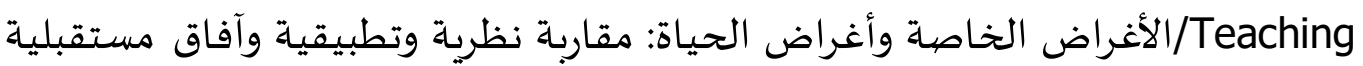
the Arabic Language for Non-native speakers in between Special and General Life purposes: A theoretical and applied approaches, and future. مجلة الدراسات اللغوية والأدبية (Journal of Linguistic and Literary Studies), 10(1).

Sanah, S. (2019). تعليم اللغة العربية لأغراض أكاديمية خاصة. Prosiding Pertemuan IImiah Internasional Bahasa Arab, 471-480.

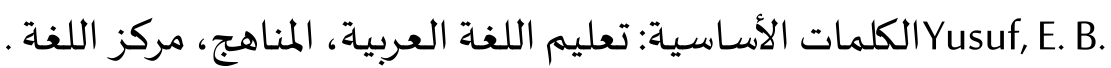

الفارسي, إ. أ. (ع . . (Y). اللغة العربية لأغراض أكاديمية بين النظرية والتطبيق Paper presented. مقالة علمية . at the

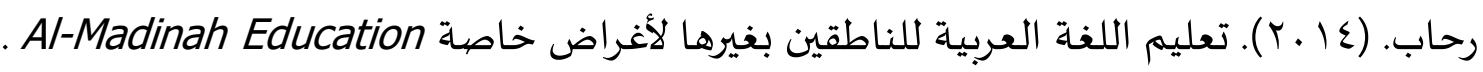

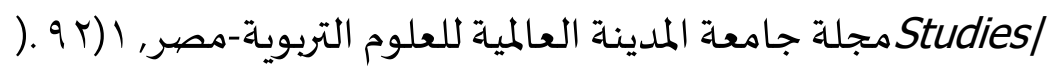

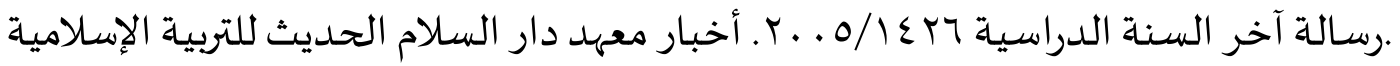

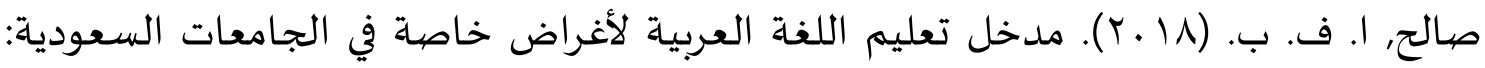
ملامح الواقع وآفاق التطوير-Y Scientific Journal of the Faculty of Education Assiut University, 452(6142), 1-21.

طعيمة, ر. أ., \& الناقة, م. ك. (7 . . Y). تعليم اللغة اتصاليا بين المناهج و الاستراتيجيات، المنظمة

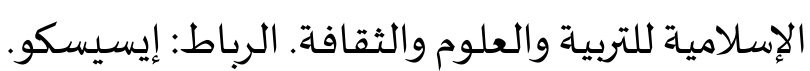

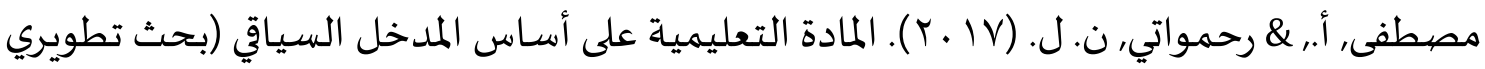

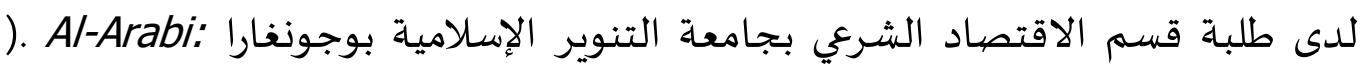
Journal of Teaching Arabic as a Foreign Language, 1(1), 1-19. 